\title{
Territórios de machos, acasalamento, distribuição e relação com plantas em Protomeliturga turnerae (Ducke, 1907) (Hymenoptera, Andrenidae)
}

Petrúcio C. R. de Medeiros ${ }^{1}$

Clemens Schlindwein ${ }^{2}$

\begin{abstract}
Male territories, mating, distribution and relation to plants in Protomeliturga turnerae (Ducke, 1907) (Hymenoptera, Andrenidae). Protomeliturga turnerae (Ducke, 1907) represents the monotypic tribe Protomeliturgini (Andrenidae, Panurginae). The species is oligolectic on flowers of Turnera L. (Turneraceae). A survey of bees on flowers of Turneraceae and of material in entomological collections showed that P. turnerae is common and endemic in Northeastern Brazil, occurring from the State of Maranhão to Alagoas. In João Pessoa, Paraíba, we studied the reproductive biology and mating behavior of $P$. turnerae and its relations to plants. At the study site, the species was univoltine with males emerging 5-8 days before the females. Soon after emergence the males established territories on flowers of Turnera subulata Smith which they occupied during several days. Parts of each territory overlapped with those of 1 to 3 other males. On the average, a territory comprised 124 flowers, 59 being shared with other males. Males showed two mating strategies: patrolling the flowers of $T$. subulata in which females collected pollen or waiting in a specific flower inside the territory for arriving females. $P$. turnerae showed multiple mating. On the average, a male mated 7 times a day, each copula lasting 3 to $25 \mathrm{sec}$. We observed 2 to 3 males attempting to copulate with the same female. At the end of anthesis of $T$. subulata the males stopped flying activity and remained inside flowers until their closure.
\end{abstract}

KEYwords. Male territories; mating behavior; Panurginae; Protomeliturga turnerae; Turneraceae.

\section{INTRODUÇÃO}

Na América do Sul, espécies da subfamília Panurginae (Andrenidae) ocorrem principalmente nos Andes e nas regiões temperadas e subtropicais, sendo menos numerosas na região Neotropical (Rozen 1967; Michener 1979, 2000; Ruz 1991).

Na revisão de Panurginae, Ruz (1991) estabeleceu a tribo Protomeliturgini contendo Protomeliturga turnerae (Ducke, 1907) como único representante. Esta abelha possui peças bucais semelhantes às abelhas de língua longa, apresentando palpos labiais com os dois artículos basais achatados e os dois distais rudimentares formando um ângulo reto com os basais. Inicialmente, DuCKE (1907) descreveu esta espécie, encontrada nos estados do Maranhão e Ceará, como Calliopsis turnerae. Um ano depois transferiu a espécie para o gênero Acamptopoeum (DUCKe 1908) e posteriormente (DUCKE 1912) criou o gênero Protomeliturga.
Informações sobre a bionomia e o comportamento reprodutivo de Panurginae da América do Sul são raras, enfatizando a descrição dos estágios imaturos e a arquitetura dos ninhos (Rozen 1967, 1970, 1989; Ruz \& Rozen 1993). Em abelhas solitárias podem ser encontradas diversas estratégias de acasalamento (Alcock 1983; Thornhill \& Alcock 1983; RouBIK 1989): a) machos patrulham nas flores visitadas pelas fêmeas ou estabelecem territórios nestas plantas (comum em abelhas oligoléticas); b) machos esperam a emergência de fêmeas nos locais dos ninhos; c) machos demarcam territórios fora das áreas dos recursos florais ou ninhos, atraindo as fêmeas com feromônios (EICKWORT \& GinsBerg 1980; RoubiK 1989; SChlumpberger \& WittMann 2000).

Neste trabalho estudamos o comportamento reprodutivo de P. turnerae e fornecemos informações sobre a sua distribuição, sazonalidade e relação com as plantas.

1. Programa de Pós-Graduação em Biologia Vegetal, Universidade Federal de Pernambuco. Av. Prof. Moraes Rego s/n, Cidade Universitária, 50670-901 Recife-PE, Brasil. Endereço Eletrônico: petruciomedeiros@ig.com.br

2. Departamento de Botânica, Universidade Federal de Pernambuco. Av. Prof. Moraes Rego s/n, Cidade Universitária, 50670-901 Recife-PE, Brasil. Endereço Eletrônico: schlindw@ufpe.br 


\section{MATERIAL E MÉTODOS}

Local de estudo. O estudo foi realizado de março de 1999 a fevereiro de $2001 \mathrm{em}$ áreas experimentais da Empresa Estadual de Pesquisas Agropecuárias da Paraíba (EMEPA). O local de estudo fica $7^{\circ} 11^{\prime} 58^{\prime \prime} \mathrm{S}$ e $34^{\circ} 48^{\prime} 37^{\prime \prime} \mathrm{W}$, com $30-40 \mathrm{~m}$ de altitude, cerca de $1 \mathrm{~km}$ distante da costa e $15 \mathrm{~km}$ ao sul de João Pessoa, Paraíba, Brasil. O clima é tropical e úmido durante o ano, com um máximo de precipitação de maio a agosto. A média de pluviosidade anual é de $1.740 \mathrm{~mm}$ e a de temperatura, $25,6^{\circ} \mathrm{C}$ (Lima \& HeCKendorfF 1985). A vegetação local da área de estudo consiste de plantas ruderais e vegetação semi-natural do Tabuleiro Nordestino (formação vegetal em solo pobre e arenoso sobre a Formação Geológica Barreiras) (ANDRADELiMA 1960).

Além disso, foram realizadas viagens de coleta a várias regiões de Alagoas, Pernambuco, Paraíba e Rio Grande do Norte para conhecer a distribuição de Protomeliturga turnerae. Estas informações foram completadas por um levantamento em coleções entomológicas das Universidades Federais de Pernambuco e da Paraíba.

Sazonalidade e atividade de vôos diários. No local de estudo foram feitas coletas de abelhas em flores de Turnera subulata Smith (Turneraceae) ao longo do ano para determinar a sazonalidade de $P$. turnera. Dados complementares foram obtidos de espécimes de coleções entomólogicas. Para conhecer o padrão de atividade diária foi medida a freqüência dos machos e fềmeas nas flores durante 50 horas de observação em 10 dias não consecutivos, distribuídos aleatoriamente ao longo do período do estudo.

Flores visitadas. Foram realizadas coletas de visitantes florais, também em flores de outras famílias de plantas, para verificar o espectro de plantas relacionadas a $P$. turnerae. A fidelidade das abelhas às flores de Turnera subulata foi avaliada pela análise da carga polínica de 10 fêmeas. Cada indivíduo foi armazenado em frasco separado para evitar contaminação com pólen de outras abelhas. O pólen foi transferido para lâminas com gelatina glicerinada corada com fucsina e selada com parafina. Foram contados 300 grãos de pólen por carga polínica e calculada a média e o desvio padrão de flores longistilas e brevistilas de T. subulata.

Estratégia reprodutiva em Protomeliturga turnerae. Machos presentes em um lote de $8 \times 7 \mathrm{~m}$, foram capturados, marcados individualmente no mesosoma com tinta permanente, soltos no local de captura e acompanhados até o seu desaparecimento. O limite de cada território dos machos foi marcado com fio de lã de cores diferentes após registrar as patrulhas dos machos nas flores. Para verificar uma eventual mudança de território ao longo do tempo o total de flores abertas durante 5 dias consecutivos foi contada, bem como o número de flores em áreas de sobreposição de territórios. Para contagem de cópulas por dia, os machos marcados foram acompanhados dentro do território em dias diferentes. $\mathrm{O}$ comportamento das abelhas foi documentado e analisado através de filmagens que, posteriormente, foram analisadas em velocidade reduzida. Espécimes-testemunho encontramse depositados na coleção Entomológica do Laboratório de Ecologia Vegetal da Universidade Federal de Pernambuco.

\section{RESULTADOS}

Distribuição. Protomeliturga turnerae ocorre nos estados de Alagoas, Ceará, Maranhão, Paraíba, Pernambuco, Rio Grande do Norte e Sergipe (Fig. 1).

Espécimes representativos examinados (números da Coleção Entomológica do Laboratório de Ecologia Vegetal da UFPE entre parênteses; $\mathrm{f}=$ fêmea, $\mathrm{m}=$ macho). BRASIL. Rio Grande do Norte: Canguaretama, BR 101, 7.V.1999, P. Medeiros (5340)(m); Tíbau do Sul, Praia da Pipa, 16.VII.2000, P. Medeiros (3248)(m), Serra Negra do Norte, Estação Ecológica do Seridó,

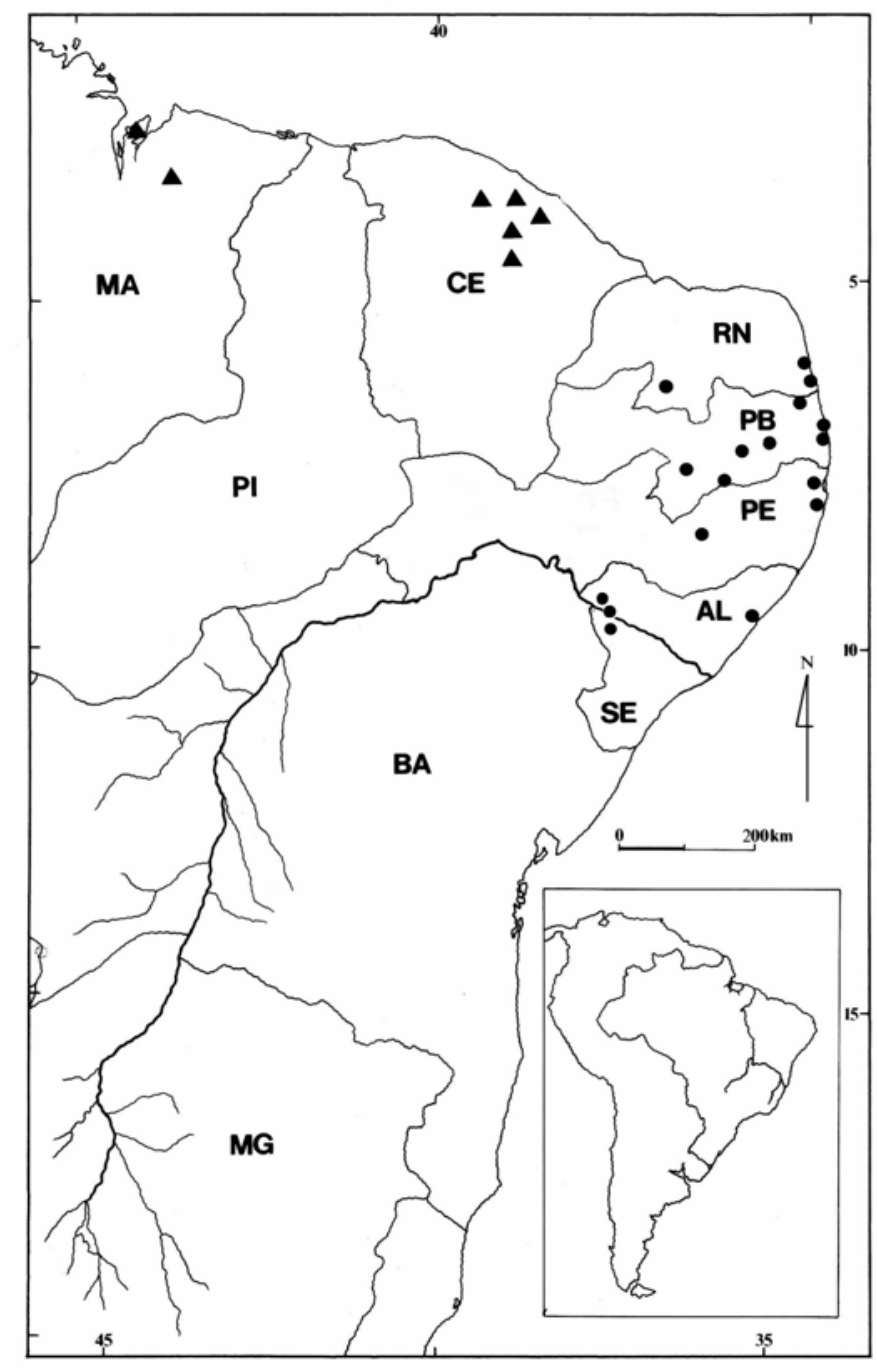

Fig. 1. Mapa de distribuição de Protomeliturga turnerae. $\mathbf{\Delta}=$ Ocorrências citadas por Ducke $\bullet=$ Ocorrências verificadas neste trabalho. 


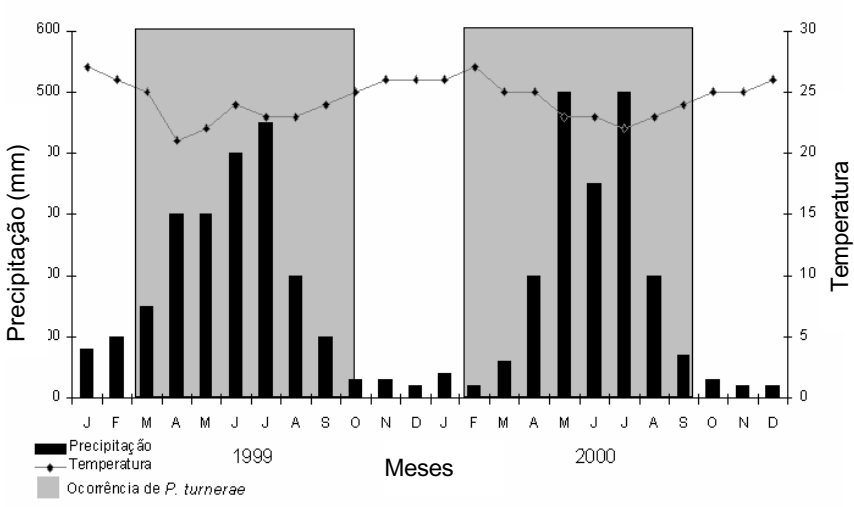

Fig. 2. Dados pluviométricos e de temperatura na área de estudo de janeiro 1999 a dezembro 2000 (fonte EMEPA) e ocorrência de Protomeliturga turnerae nas flores de Turnera subulata.

5.VI.2002, C. Schlindwein (7933) (m), mesmo local e coletor 6.VI.2002 (8488)(f). Paraíba: Barra de São Miguel, BR 104, 7.V.1999, P. Medeiros (4045)(m); Boqueirão, BR 104, 17.II.2000, P. Medeiros (3286)(m); Cabedelo, Intermares, 16.II.2001, P. Medeiros (3295)(m); João Pessoa, Costa do Sol, 18.VIII.1999, P. Medeiros (3199)(f); Queimadas, BR 104, 7.V.1999, P. Medeiros (3234)(m); Mamanguape, Res. Biol. Guaribas, 13.I.2000, P. Medeiros (2041)(f); São João do Cariri, 1.VI.94, C.M.L. Aguiar (UFPB)(f). Pernambuco: Caruaru, Brejo dos Cavalos, 7.VIII.1999, P. Medeiros (3301)(m); Goiana, BR 101, 7.V.2000, P. Medeiros (4075)(m); Paulista, BR 101, 7.V.1999, P. Medeiros (5337)(m); Taquaritinga do Norte, BR 104, 7.V.1999, P. Medeiros (5338)(f). Sergipe: Canindé do São Francisco, 30.VIII.2002, D. Moura (8040) (f), mesmos dados 8908 (f), 8776 (m), 8962 (m). Alagoas: Maceió, Barra de São Miguel, 7.VIII.1992, C. Schlindwein (9012)(f); Piranhas, Bairro Xingó, 21.IV.2002, C. Schlindwein (8780) (m); Olho D'Água do Casado, 3.VII.2002, D. Moura (8757) (f), mesmo local e coletor 27.VIII.2002 (8592) (m) e 8618 (f).

Material-tipo. Não examinado. Ducke (1907) não especificou o número e o sexo dos exemplares quando descreveu Calliopsis turnerae, indicando como procedências: BRASIL. Maranhão: São Luis, Codó. Ceará: Baturité, Quixadá, Humaitá, Miguel-Calmon, Caridade.

De acordo com OBREChT \& Huber (1993) o material-tipo de P. turnerae está depositado no Museu Paraense Emílio Goeldi, Belém (MPEG) (lectótipo: Maranhão: São Luís, 8.VI.1907, Ducke; lectoalótipo: mesmo local e coletor, 6.VI.1907, designado por Moure \& Michener em 1955). Material com a etiqueta "type" com a mesma procedência do lectótipo foi depositado no Zoologisches Museum der HumboldtUniversität, Berlim (ZMHU) e no Natural History Museum, Bern (NMBE).

Sazonalidade e atividade diária de vôo. No local de estudo foram registrados machos e fêmeas de Protomeliturga turnerae de março a outubro de 1999 e de fevereiro a setembro de 2000, que corresponde ao período chuvoso (Fig. 2). Em ambos os

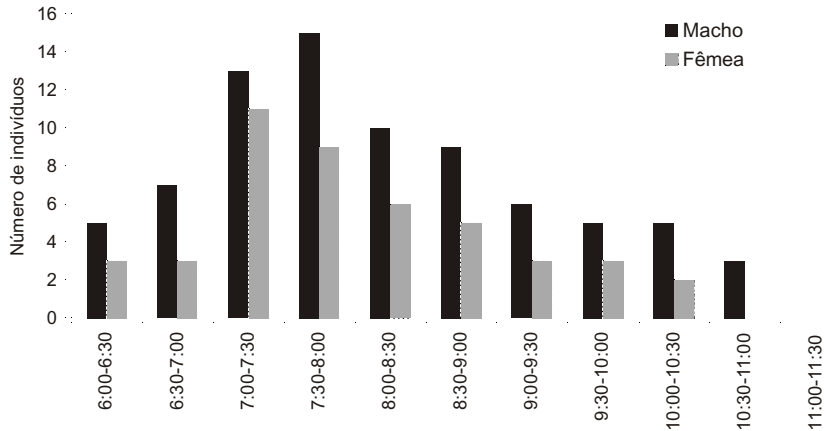

Fig. 3. Freqüência de visitas de machos e fêmeas de Protomeliturga turnerae em flores de Turnera subulata.

anos os machos foram registrados de 5-8 dias antes das fêmeas. Em outros locais de Pernambuco e da Paraíba, indivíduos de $P$. turnerae foram capturados em janeiro de 1999 e em fevereiro de 2000.

A atividade diária de vôo de machos e fêmeas de P. turnerae foi das 6:00 às 11:00 h, quando as flores de Turnera subulata estiveram abertas (Fig. 3). O pico de atividade dos machos foi entre 7:00 e 8:00 h, coincidindo com o horário de maior freqüência das fêmeas.

Flores visitadas. Fêmeas e machos de $P$. turnerae foram registrados quase exclusivamente em flores de $T$. subulata (94\%). Além disso, foram encontradas esporadicamente em flores de Piriqueta duartiana (A. St.-Hil., Juss. \& Camb.) Urban (Turneraceae) e Gaya gaudichaudiana A. St.-Hil. (Malvaceae). T. subulata apresenta ampla distribuição como planta ruderal no Nordeste do Brasil.

A antese de T. subulata inicia às 6:00 h e termina por volta das 11:00 h. As flores desta espécie são distílicas. Os grãos de pólen dos morfos longistilos e brevistilos apresentam diferenças no tamanho e na ornamentação. A análise da carga polínica das fêmeas mostrou que estas coletaram pólen

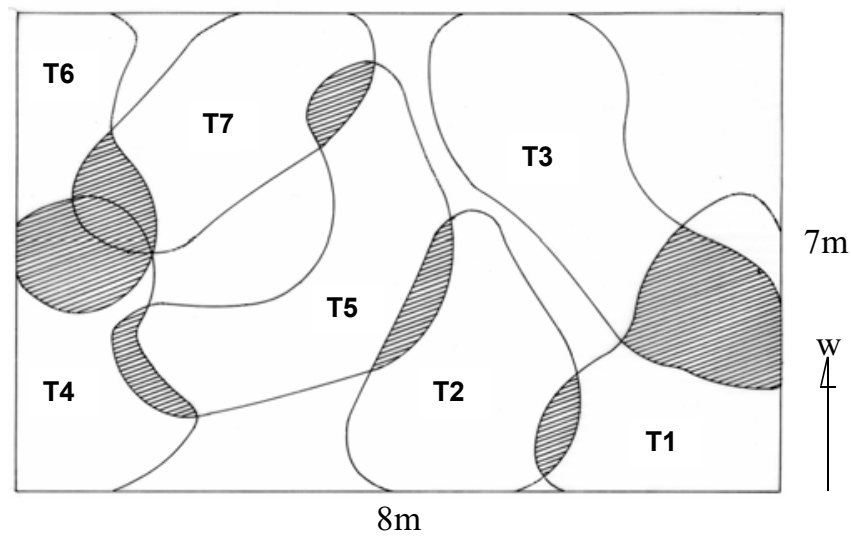

Fig. 4. Distribuição de sete territórios de machos de Protomeliturga turnera (T1-T7) em um área de $8 \times 7 \mathrm{~m}^{2}$ na EMEPA, João Pessoa. As áreas achoriadas indicam locais de sobreposição de territórios. 
Tabela I. Características dos territórios de 15 machos de Protomeliturga turnerae (Ducke, 1907) em João Pessoa, Paraíba, em abril de 2000.

\begin{tabular}{cccc}
\hline Macho & $\begin{array}{c}\text { Ocupação do } \\
\text { território } \\
(\text { dias })\end{array}$ & $\begin{array}{c}\text { Tamanho do } \\
\text { território } \\
\left(\mathrm{m}^{2}\right)\end{array}$ & $\begin{array}{c}\mathrm{N}^{\mathrm{o}} \text { de flores } \\
\text { no território } \\
(\mathrm{min}-\mathrm{max})\end{array}$ \\
\hline 1 & 6 & 2,8 & $132(110-154)$ \\
2 & 8 & 2,7 & $120(100-140)$ \\
3 & 14 & 3,3 & $130(100-161)$ \\
4 & 6 & 3 & $106(85-128)$ \\
5 & 6 & 3 & $121(90-152)$ \\
6 & 8 & 3,1 & $135(110-160)$ \\
7 & 8 & 3,1 & $124(95-153)$ \\
8 & 12 & 3,2 & $110(80-140)$ \\
9 & 6 & 2,2 & $100(90-110)$ \\
10 & 9 & 3,7 & $130(110-150)$ \\
11 & 14 & 2,8 & $111(85-137)$ \\
12 & 14 & 3,5 & $142(120-164)$ \\
13 & 8 & 3,7 & $150(120-180)$ \\
14 & 10 & 2,1 & $105(80-130)$ \\
15 & 10 & 2,6 & $148(125-171)$ \\
\hline Média & - & 3,0 & 124 \\
\hline
\end{tabular}

exclusivamente nas flores daquela espécie. A percentagem média de pólen de flores brevistilas foi de 55,1\% (DP=9,8; $\mathrm{n}=10)$ e das flores longistilas 44,9\% (DP=9,8; $\mathrm{n}=10)$. Machos e fêmeas visitaram indiscriminadamente flores brevistilas e longistilas.

O tempo médio de coleta de pólen por flor foi de $11,4 \mathrm{~s}$ $(\mathrm{DP}=4,3 ; \mathrm{n}=20)$. Na visita a flores brevistilas as fêmeas pousaram sobre as anteras dos estames longos, coletaram pólen com as pernas anteriores, ficando com a cabeça voltada para o interior da flor. Inicialmente, os grãos de pólen permaneceram aderidos à região ventral do meso- e metasoma. Depois de algumas visitas a fêmea transfere este pólen para a escopa, pousada nas pétalas. Nas flores longistilas as fêmeas pousam sobre os estígmas contactando-os com a parte ventral do corpo. Em seguida coletam pólen dos estames curtos com as pernas anteriores e com o labro, que apresenta pêlos rígidos voltados para baixo. Logo após, avançam em direção à base das pétalas para tomar néctar. Depois das visitas às flores, $\mathrm{o}$ pólen aderiu no vértice, no labro e no pronoto.

Comportamento reprodutivo dos machos. A marcação individual de machos mostrou que eles demarcam e mantêm territórios. Os indivíduos marcados ocuparam o mesmo território até 14 dias. O tamanho médio dos territórios foi de 3 $\mathrm{m}^{2}$. O número médio de flores de $T$. subulata por território foi de $124(\mathrm{DP}=15,7 ; \mathrm{n}=15)$ (Tabela I).

Os territórios dos machos se sobrepõem (Fig. 4). Cerca de $50 \%$ das flores de um território pertenceram exclusivamente a um macho e o restante das flores faz parte de territórios de outros machos (Tabela II). Até três competidores compartilham flores do território de um macho. O primeiro competidor compartilha em média cerca de $30 \%$ das flores presentes, e o segundo $20 \%$. O compartilhamento de flores com o terceiro competidor foi diminuto (Tabela III).

Pousados nas flores, os machos assumiram uma posição de defesa com as pernas anteriores levantadas e as mandíbulas abertas. Algumas vezes afugentaram o macho invasor voando em sua direção.

Os machos iniciaram a atividade de vôo poucos minutos antes da antese de T. subulata e pousaram em uma flor ainda fechada. Às 6:00 h, no início da antese, conseguiram espaço suficiente para penetrar entre as pétalas semi-abertas para obtenção de néctar. Posteriormente, durante os vôos de patrulha, voltaram repetidamente para esta flor, permanecendo por períodos prolongados dentro da flor. Denominamos tal flor como "flor de base". Entre 6:00-7:00 h os machos permaneceram a maior parte do tempo nesta flor. Após tomar néctar pela primeira vez, realizaram vôos de curta duração aumentando-os progressivamente até a delimitação do território, cerca de $1 \mathrm{~h}$ após a abertura da flor. Geralmente, retornaram à "flor de base" ou, raramente, à outra flor próxima.

Os vôos de patrulha iniciaram por volta das 7:00 h. Após terem deixado a "flor de base" os machos inspecionaram, em

Tabela II. Número de flores de Turnera subulata em territórios de sete machos marcados de Protomeliturga turnerae em 5 dias consecutivos. Número total de flores, número de flores compartilhadas com outros machos e número de flores não compartilhadas. Área de observação 7 x 8 m.

\begin{tabular}{|c|c|c|c|c|c|c|c|c|c|c|c|c|c|c|c|c|c|c|}
\hline \multirow[t]{2}{*}{$\begin{array}{l}\text { Macho } \\
\text { / Dia }\end{array}$} & \multicolumn{6}{|c|}{$\begin{array}{l}\mathrm{N}^{\circ} \text { total de flores no } \\
\text { território }\end{array}$} & \multicolumn{6}{|c|}{$\begin{array}{l}\mathrm{N}^{\circ} \text { de flores compartilhadas } \\
\text { com outros machos }\end{array}$} & \multicolumn{6}{|c|}{$\begin{array}{c}\mathrm{N}^{\mathrm{o}} \text { de flores não compartilhadas } \\
\text { com outros machos }\end{array}$} \\
\hline & $1^{\mathrm{o}}$ & $2^{o}$ & $3^{o}$ & $4^{\circ}$ & $5^{\circ}$ & $\mathrm{x}$ & $1^{\mathrm{o}}$ & $2^{o}$ & $3^{\circ}$ & $4^{o}$ & $5^{\circ}$ & $\mathrm{x}$ & $1^{o}$ & $2^{o}$ & $3^{\circ}$ & $4^{\circ}$ & $5^{\circ}$ & $\mathrm{x}$ \\
\hline 1 & 180 & 115 & 150 & 97 & 107 & 130 & 110 & 45 & 74 & 47 & 39 & 63 & 70 & 70 & 76 & 50 & 68 & 67 \\
\hline 2 & 132 & 127 & 108 & 114 & 122 & 120 & 67 & 42 & 61 & 76 & 80 & 65 & 65 & 85 & 47 & 38 & 42 & 55 \\
\hline 3 & 111 & 145 & 133 & 122 & 113 & 125 & 66 & 95 & 86 & 90 & 62 & 80 & 45 & 50 & 47 & 32 & 51 & 45 \\
\hline 4 & 124 & 117 & 130 & 110 & 115 & 119 & 41 & 52 & 39 & 40 & 50 & 44 & 83 & 65 & 91 & 70 & 65 & 75 \\
\hline 5 & 124 & 145 & 114 & 123 & 121 & 125 & 44 & 70 & 69 & 71 & 61 & 63 & 80 & 75 & 45 & 52 & 60 & 62 \\
\hline 6 & 121 & 114 & 98 & 103 & 110 & 109 & 65 & 44 & 50 & 57 & 57 & 54 & 56 & 70 & 48 & 46 & 53 & 54 \\
\hline 7 & 135 & 123 & 112 & 127 & 127 & 125 & 59 & 56 & 30 & 37 & 46 & 45 & 76 & 67 & 82 & 90 & 81 & 79 \\
\hline Média & 132 & 126 & 120 & 113 & 116 & 122 & 64 & 57 & 58 & 59 & 56 & 59 & 67 & 68 & 52 & 54 & 60 & 63 \\
\hline
\end{tabular}


Tabela III. Sobreposição de flores de Turnera subulata nos territórios de 7 machos de Protomeliturga turnerae em 5 dias consecutivos.

\begin{tabular}{|c|c|c|c|c|c|c|c|c|c|c|c|c|c|c|c|c|c|c|}
\hline \multirow[t]{2}{*}{$\begin{array}{l}\text { Macho } \\
\text { / Dia }\end{array}$} & \multicolumn{6}{|c|}{$\begin{array}{l}\text { Compartilhamento de flores } \\
\text { com o } 2^{\circ} \text { macho }\end{array}$} & \multicolumn{6}{|c|}{$\begin{array}{l}\text { Compartilhamento de flores } \\
\text { com o } 3^{\circ} \text { macho }\end{array}$} & \multicolumn{6}{|c|}{$\begin{array}{l}\text { Compartilhamento de flores } \\
\text { com o } 4^{\circ} \text { macho }\end{array}$} \\
\hline & $1^{\mathrm{o}}$ & $2^{\circ}$ & $3^{\circ}$ & $4^{o}$ & $5^{\circ}$ & $X$ & $1^{\mathrm{o}}$ & $2^{o}$ & $3^{\circ}$ & $4^{o}$ & $5^{\circ}$ & $X$ & $1^{\circ}$ & $2^{\circ}$ & $3^{\circ}$ & $4^{o}$ & $5^{\circ}$ & $\mathrm{x}$ \\
\hline 1 & 70 & 30 & 40 & 35 & 25 & 40 & 40 & 15 & 34 & 12 & 14 & 23 & - & - & - & - & - & - \\
\hline 2 & 32 & 30 & 35 & 40 & 80 & 43 & 35 & 12 & 26 & 36 & - & 27 & - & - & - & - & - & - \\
\hline 3 & 66 & 95 & 86 & 90 & 62 & 80 & - & - & - & - & - & - & - & - & - & - & - & - \\
\hline 4 & 41 & 30 & 10 & 10 & 21 & 22 & - & 22 & 12 & 30 & 29 & 23 & - & - & 17 & - & - & - \\
\hline 5 & 15 & 35 & 15 & 71 & 61 & 40 & 29 & 25 & 27 & - & - & 27 & - & 10 & 27 & - & - & - \\
\hline 6 & 65 & 44 & 27 & 30 & 57 & 45 & - & - & 23 & 27 & - & - & - & - & - & - & - & - \\
\hline 7 & 59 & 36 & 10 & 15 & 46 & 33 & - & 20 & 12 & 22 & - & 18 & - & - & 8 & - & - & - \\
\hline Média & & & & & & 43 & & & & & & 23 & & & & & & - \\
\hline
\end{tabular}

vôo rápido, cerca de 60 flores em cada vôo de patrulha sem visitá-las. O tempo médio desses vôos foi de 79 s $(\mathrm{DP}=33$; $\mathrm{n}=25$ ). Esporadicamente, pousaram por até $8 \mathrm{~s}$ nas pétalas de uma flor sem tocar estames ou estígmas e sem coletar néctar. A cada 50-65 flores inspecionadas, pousaram em uma flor contactando estames e estígmas e sugaram néctar. Na maioria dos vôos de patrulha, mostraram a seguinte seqüência: repouso na flor de base, patrulha, coleta de néctar, patrulha, repouso na flor de base. Uma ou duas vezes por dia, os machos deixaram seus territórios para visitar flores de T. subulata próximas, retornando alguns segundos depois e reiniciando a patrulha. Durante os vôos de patrulha, não foram observados machos pousados em ramos ou folhas.

Acasalamento. Foram observadas duas estratégias dos machos de P. turnerae para encontrarem as fêmeas: 1) procura ativa nos vôos de patrulha dentro do território, onde se lançam sobre a fêmea que coleta pólen e 2) espera, geralmente na flor de base, à chegada de uma fêmea.

Machos e fêmeas copularam diversas vezes durante um dia. Não foi observada rejeição de machos por fêmeas que já haviam copulado anteriormente. Os machos copularam em média 7 vezes por dia $(\mathrm{DP}=1,8 ; \mathrm{n}=15)$ (Fig. 5). O número de cópulas por dia não mostrou relação com a quantidade de flores presentes no território de um macho. Por exemplo, o macho ${ }^{\circ} 11$ que ocupou um território com média de 111 flores, apresentou o dobro de cópulas em relação ao macho $\mathrm{n}^{\circ} 1 \mathrm{com}$ um território maior (Tabela I). Cada cópula durou 3-25 s $(\mathrm{DP}=6,3 ; \mathrm{n}=71)$. Foram observadas tentativas de cópulas de 2

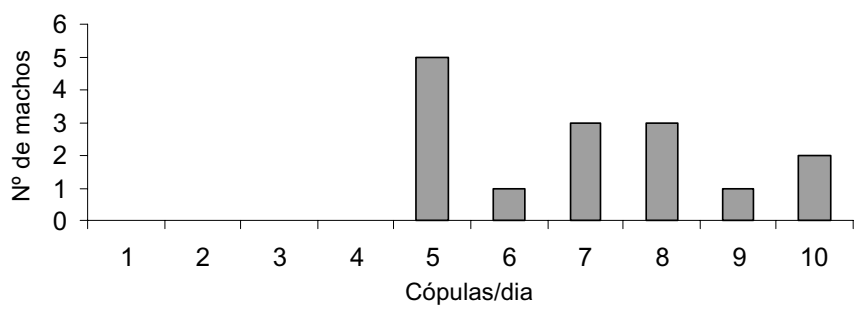

Fig. 5. Número de cópulas que um macho de Protomeliturga turnerae realiza diariamente $(\mathrm{N}=15$ machos $)$. a 3 machos com a mesma fêmea nas áreas de sobreposição dos territórios. Entre 6:00 h e 7:00 h, antes do início do patrulhamento regular, foram registradas as primeiras cópulas, principalmente nos dias de pouca nebulosidade. O horário de maior freqüência de cópulas (7:00-7:30, 38\% das cópulas) coincidiu com o pico de atividade de coleta das fêmeas (Fig. $6)$.

Durante a cópula, o macho segurou a fêmea pelos flancos do mesosoma com as pernas anteriores e os do metasoma com as pernas médias. Desta maneira, imobilizou a fêmea prendendo suas asas com as pernas anteriores. Em seguida, o macho deslizou o corpo para trás, curvou o metasoma para encaixe das genitálias e realizou rápidos bombeamentos abdominais (Fig. 7). Em alguns casos um outro macho inseriuse entre o casal em posição de cópula. Às vezes, o conjunto de abelhas rolou sobre as pétalas, caiu da flor e separou-se no ar.

Um macho marcado, após pousar em uma flor de $T$. subulata, esfregou suas pernas médias e posteriores nos lados dos tergos metasomais. Em seguida, andou sobre as pétalas passando os flancos metasomais sobre estas e retornou ao vôo de patrulha. Cinco segundos após, uma fêmea pousou na mesma flor e esfregou seu metasoma nestas pétalas e começou

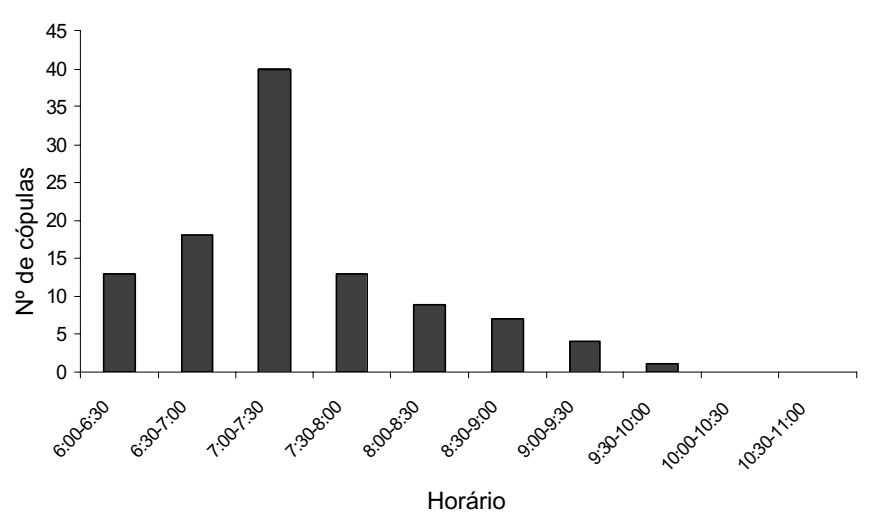

Fig. 6. Número de cópulas de 15 machos individualmente marcados de Protomeliturga turnerae durante a antese de Turnera subulata por horário. Cópulas agrupadas para intervalos de 30 minutos. 


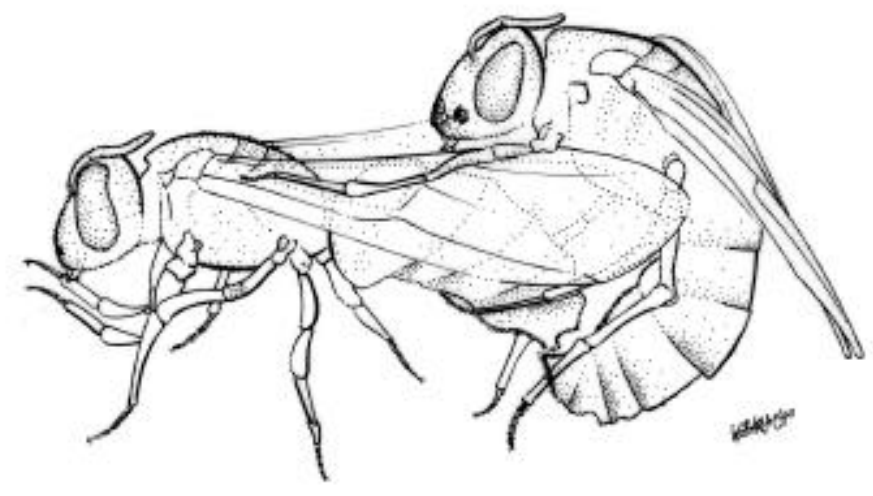

Fig. 7. Posição de cópula de Protomeliturga turnerae.

a esfregar as pernas médias e posteriores nos tergos metasomais. Logo depois, o macho marcado retornou do vôo de patrulha e pousou sobre a fêmea iniciando a cópula.

No final da antese de T. subulata (10:30-11:00 h) os machos param de voar e permanecem imóveis, cada um dentro de uma flor de seu território, até que esta se feche completamente. Em um caso foi observado que no dia seguinte, entre 4:30 e 5:00 h, o macho abriu um orifício na base da corola com as mandíbulas e deixou a flor à procura de uma "flor de base", ainda fechada.

\section{DISCUSSÃO}

Protomeliturga turnerae apresenta distribuição ampla no Nordeste do Brasil e ocorre com grande abundância no litoral entre o Maranhão e Alagoas. Sua ocorrência em Brejos de Altitude e na Caatinga parece mais restrita já que em diversos locais onde indivíduos de Turnera estiveram presentes, a espécie não foi registrada. Devido à carência de levantamentos de abelhas no Nordeste do Brasil, a espécie foi considerada restrita aos Estados de Maranhão e Ceará (Ducke 1912; RuZ 1991). Segundo Silveira et al. (2002) a espécie também ocorre na Bahia.

A espécie é oligolética. A relação íntima com T. subulata também se mostra no estabelecimento dos territórios dos machos entre as plantas, além do uso das flores como local de cópula. Oligoletia é citada para diversas espécies de Panurginae mas, na maioria, as relações com plantas ainda não são conhecidas. Relações de oligoletia são encontradas em Anthrenoides meridionalis (Schrottky, 1906) com flores de Oxalis (Oxalidaceae) (Schlindwein 1998; Alves-dos-Santos 1999), Callonychium petuniae Cure \& Wittmann, 1990 com flores de Petunia (Solanaceae) (Wittmann et al. 1990), Arhysosage cactorum Moure, 1999 com flores de Notocactus, Gymnocalycium e Opuntia (Cactaceae) (Schlindwein \& Wittmann 1995, 1997), Neffapis longilingua Ruz, 1995 com flores de Malesherbia humilis (Malesherbiaceae) (Rozen \& Ruz 1995) e diversas espécies de Panurgillus Moure, 1998 com flores de ervas e arbustos pequenos das famílias Apiaceae, Asteraceae, Malvaceae, Oxalidaceae (Schlindwein \& Moure
1998; AlvES-DOS-SANTOS 1999a).

Em espécies de abelhas especializadas, cujas fêmeas visitam flores de poucas espécies de plantas, os machos freqüentemente patrulham nestas flores (PARKER 1978; Barrows 1978; Thornhill \& Alcock 1983; Wittmann et al. 1990; Schlindwein \& Wittmann 1995; Alves-dos-Santos 1999b).

O estabelecimento de territórios em abelhas tem a função de monopolizar um local de acasalamento (Ацсоск et al. 1978). No início de suas atividades os machos devem, primeiramente, estabelecer os territórios que são permanentemente mantidos por eles. A delimitação dos territórios entre os machos deve ser um processo dinâmico, acompanhado com defesa de áreas até que definam os territórios. Uma vez estabelecidos, os machos não necessitam investir muita energia na sua demarcação diária. Posteriormente, a competição e defesa do território ficam restritas somente às áreas de sobreposição com outros machos. Comportamento semelhante foi observado em Andrena erigeniae Robertson, cujos machos mantém territórios e compartilham áreas com outros machos coespecíficos (BARROws 1978); porém o autor não especifica se estes machos conservam os mesmos territórios no dia seguinte.

Os machos antecederam ao aparecimento das fêmeas em uma até duas semanas. A protandria favorece o sucesso reprodutivo de machos em espécies onde as fêmeas somente são fecundadas no início da sua fase adulta. No caso de $P$. turnerae, que possui um sistema de acasalamento múltiplo e no qual as fêmeas copulam várias vezes por dia, o valor seletivo da protandria não é relacionado com as primeiras cópulas. Neste caso, deve estar vinculado com a velocidade do estabelecimento de território, que provavelmente seja mantido durante toda a vida do macho. O macho nascido no início do período de atividade desta espécie univoltina deve ser favorecido com o território mais atrativo, aumentando, desta maneira, o seu sucesso reprodutivo.

A combinação de patrulha e espera por fêmeas em determinadas flores para acasalamento também ocorre em outras espécies de Panurginae: Calliopsis subalpina (Cockerell) (Rozen 1970), Perdita texana Cresson (BARrows et al. 1976), Cephalurgus anomalus Moure \& Oliveira, 1962 (Eickwort \& Ginsberg 1980) e Callonychium petuniae (WitTMAnN et al. 1990). Cópulas múltiplas são conhecidas em Apis andreniformis (Smith, 1858), Apis cerana Fabricius, 1793, Arhysosage cactorum Moure, 1999, A. flava Moure, 1958, Callonychium petuniae, Perdita texana, Perdita albipennis Cresson, Anthidium illustre Cresson e Anthidiellum notatum (Latreille) (Wittmann et al. 1990; Roig-Alsina 1993; Schlindwein \& Wittmann, 1995).

Em algumas espécies poliândricas de Panurginae que apresentam cópulas longas, os machos acompanham a fêmea em posição de cópula de flor em flor, enquanto a fêmea prossegue coletando pólen (Rozen 1958; WitTMANN et al. 1990; Schlindwein \& Wittmann 1995, 1997; Morato \& Campos 2000). O acompanhamento da fêmea até a entrada do ninho tem sido interpretado como impulsionado pela competição entre machos (Wittmann et al. 1990; RoIG-Alsina 1993). 
Em muitas espécies de abelhas é necessário que haja a eversão do saco endofálico para inseminar a fêmea. Contudo, a fêmea pode ser capaz de controlar a eversão do saco endofálico, de forma que a cópula não resulte, necessariamente, na sua inseminação (RoIG-Alsina 1993). Isto significa uma possibilidade de "female choice".

Depressões laterais no segundo tergo abdominal de abelhas de Panurginae (SChlindwein \& Moure 1998) são associadas à presença de glândulas (RAmos et al. 2002). Nossa observação do macho que esfregou as pernas nos lados do metassoma, pode ser uma indicação que este possivelmente transfere as secreções acumuladas dessas glândulas para os pêlos das pernas médias e/ou posteriores. Estas provavelmente sejam utilizadas na marcação do território. Outra função poderia ser de feromônio sexual, já que uma fêmea pousou numa pétala na qual um macho tinha aplicado a secreção alguns segundos antes.

Agradecimentos. Aos diretores da Empresa Estadual de Pesquisas Agropecuárias da Paraíba (EMEPA) pelo acesso às dependências da Estação Experimental de Mangabeira. Ao Celso Feitosa Martins (UFPB) e Isabel Cristina Machado (UFPE) pelas valiosas sugestões. À Evelise Locatelli, Reisla Oliveira Darrault e Celso Feitosa Martins pela colaboração em campo. Ao CNPq pelo apoio financeiro.

\section{REFERÊNCIAS}

Alcock, J. 1983. Animal behavior, an evolutionary approach. $5^{\text {th }}$ ed. Sunderland, Sinauer Associates Inc. Publishers, 625 p.

Alcock, J.; E. M. Barrows; G. Gordh; L. J. HubBard; L. Kirkendall; D. W. Pyle; T. L. Ponder \& F. G. Zalom. 1978. The ecology and evolution of male reprodutive behavior in the bees and wasps. Zoological Journal of the Linnean Society 64: 293-326.

Alves-Dos-SAnTos, I. 1999a. Abelhas e plantas melíferas da mata atlântica, restinga e dunas do litoral norte do estado do Rio Grande do Sul, Brasil. Revista Brasileira de Entomologia 43 (3/4): 191-223.

Alves-dos-Santos, I. 1999b. Aspectos morfológicos e comportamentais dos machos de Ancyloscelis Latreille (Hymenoptera, Apoidea). Revista Brasileira de Zoologia 16(supl. 2): 37-43.

Andrade-Lima, D. 1960. Estudos fitogeográficos de Pernambuco. Arquivo do Instituto de Pesquisa Agronômica 5: 305-341.

Barrows, E. M. 1978. Male behavior in Andrena erigeniae (Hymenoptera: Andrenidae) with comparative notes. Journal of the Kansas Entomological Society 51(4): 798-806.

Barrows, E. M.; M. R. Сhabot; C. D. Michener \& T. P. Snyder. 1976. Foraging and mating behavior in Perdita texana (Hymenoptera: Andrenidae). Journal of the Kansas Entomological Society 49: 275-279.

Ducke, A. 1907. Contribution à la connaissance de la faune hyménoptérologique du Nort-Est du Brèsil I. Revue d'Entomologie 26: 73-96.

DuCKe, A. 1908. Contribution à la connaissance de la faune hyménoptérologique du Nort-Est du Brèsil II. Revue d'Entomologie 27: $57-87$

DuCKE, A. 1912. Die natürlichen Bienengenera Südamerikas. Zoologische Jahrbücher, Abteilung für Systematik, Geographie und Biologie der Tiere 34: 51-116.

EICKWORT, G. C. \& H. S. GinsBerg. 1980. Foraging and mating behavior in Apoidea. Annual Review of Entomology 25: 421-446.

Lima, P. L. \& W. D. Heckendorff. 1985. Climatologia. In: Atlas Geográfico da Paraíba. João Pessoa, Ed. Grafset, 99 p.
Michener, C. D. 1979. Biogeography of the bees. Annals of the Missouri Botanical Garden 66: 277-347.

Michener, C. D. 2000. The Bees of the World. Baltimore and London, The Johns Hopkins University Press, $913 \mathrm{p}$.

Morato, E. F. \& L. A. O. CAmpos. 2000. Partição de recursos florais de espécies de Sida Linnaeus e Malvastrum coromandelianum (Linnaeus) Garcke (Malvaceae) entre Cephalurgus anomalus Moure \& Oliveira (Hymenoptera, Andrenidae, Panurginae) e Melissoptilia cnecomala (Moure) (Hymenoptera, Apidea, Eucerini). Revista Brasileira de Zoologia 17(3): 705-727.

OвRеснт, E. \& C. HuBER. 1993. Ducke type specimens and other Brazilian insect types in the Emil. A. Goeldi collection in the Natural Museum Bern (Switzeland). An annotated catalogue. Jahrbuch des Naturhistorischen Musems 11: 163-184.

Parker, G. A. 1978. Evolution of competitive mate searching. Annual Review of Entomology 23: 173-196.

Ramos, K. S.; C. G. Santos; C. Schlindwein \& B. Blochtein. 2002. Glândulas tegumentares associadas às fóveas tergais de três espécies de Panurgillus Moure, 1998 (Andrenidae; Panurginae). Anais do Encontro sobre Abelhas 5: 277.

Roig-Alsina, A. 1993. The evolution of the apoid endophallus, its phylogenetic implications, and functional significance of the genital capsule (Hymenoptera, Apoidea). Bollettino di Zoologia 60: 169183.

Roubik, D. W. 1989. Ecology and natural history of tropical bees. New York, Cambridge University Press, 514 p.

Rozen, J. G. 1958. Monographic study of the genus Nomadopsis Ashemead (Hymenoptera: Andrenidae). University of California Publications in Entomology 15: 1-202.

Rozen, J. G. 1967. Review of the biology of panurgine bees, with observations on North American forms (Hymenoptera, Andrenidae). American Museum Novitates 2297: 1-44.

Rozen, J. G. 1970. Biology and immature stages of the panurgine bee genera Hypomacrotera and Psaenythia (Hymenoptera, Apoidea). American Museum Novitates 2416: 1-15.

Rozen, J. G. 1989. Life history studies of the "primitive" panurgine bees (Hymenoptera: Andrenidae: Panurginae). American Museum Novitates 2962: 1-27.

Rozen, J. G. \& L. Ruz. 1995. South American panurgine bees (Andrenidae: Panurginae), Part II. Adults immature stages, and biology of Neffapis longilingua, a new genus and species with on elongate glossa. American Museum Novitates 3136: 1-15.

Ruz, L. 1991. Classification and phylogenetic relationships of the panurgine bees: the Calliopsini and allies (Hymenoptera: Andrenidae). University of Kansas Science Bulletin 54: 209-256.

Ruz, L. \& J. G. Rozen. 1993. South American panurgine bees (Apoidea: Andrenidae: Panurginae), Part I. Biology, mature larva, and description of a new genus and species. American Museum Noviatates 3057: 1-12.

SchlindweIn, C. 1998. Frequent oligolecty characterizing a diverse beeplant community in a xerophytic bushland of subtropical Brazil Studies on Neotropical Fauna and Environment 33: 46-59.

Schlindwein, C. \& J. S. Moure. 1998. Panurgillus, gênero novo de Panurginae, com a descrição de quatorze espécies do Sul do Brasil (Hymenoptera, Andrenidae). Revista Brasileira de Zoologia 15(2): 397-439.

Schlindwein, C \& D. Wittmann. 1995. Specialized solitary bee as effective pollinators of South Brazilian species of Notocactus of Gymnocalycium. Bradleya 13: 25-34

Schlindwein, C \& D. Wittmann. 1997. Micro foraging routes of Bicolletes pampeana (Colletidae) and bee induced pollen presentation in Cajophora arechavaletae (Loasaceae). Acta Botanica 110: 177183.

SchlumpBerger, B. \& D. Wittmann. 2000. New odour glands in Xylocopa males (Hymenoptera: Apoidea: Anthophoridae). Journal of Hymenopterological Research 9(2): 363-369.

Silveira, F. A.; G. A. R. Melo \& E. A. B. Almeida. 2002. Abelhas brasileiras. Sistemática e identificação. Belo Horizonte, 253p. Thornhill, R. \& J. Alcock. 1983. The evolution of insect mating 
systems. Cambridge, Harvard Univ. Press, 547p.

Wittmann, D.; R. Radtke; J. R. Cure \& M. T. Schifino-Wittmann. 1990.

Coevolved reprodutive strategies in the oligolectic bee Callonychium petuniae (Apoidea, Andrenidae) and thee purple flowered Petunia species (Solanaceae) in Southern Brazil. Zeitschrift für zoologische Systematik und Evolutionsforschung 28: 157165 . 